\title{
Transcription factor PU.1 and immune cell differentiation (Review)
}

\author{
GUANGLAN LI $^{1,2}$, WENKE HAO ${ }^{1}$ and WENXUE HU ${ }^{1}$ \\ ${ }^{1}$ Department of Nephrology, Guangdong Provincial People's Hospital, Guangdong Academy of \\ Medical Sciences, Guangdong Provincial Geriatrics Institute, Guangzhou, Guangdong 510080; \\ ${ }^{2}$ Shantou University Medical College, Shantou, Guangdong 515041, P.R. China
}

Received July 24, 2020; Accepted October 6, 2020

DOI: $10.3892 /$ ijmm.2020.4763

\begin{abstract}
The transcription factor PU.1, an important member of the ETS family, plays a significant role in the differentiation of immune cells, which include macrophages, neutrophils, dendritic cells, T lymphoid cells, B lymphoid cells and so on. Immune cells are involved in the occurrence and development of diseases, including inflammatory diseases, neoplastic diseases and immune diseases. Therefore, it is particularly crucial to elucidate the roles and mechanisms of PU.1 in immune cells. The elucidation of these mechanisms may lead to the development of more effective therapeutic strategies for the treatment of inflammatory diseases and immune-mediated diseases mediated by various immune cells. With the development of molecular biology, the mechanisms of PU.1 in immune cell differentiation have been further explained. Different levels of PU.1 expression determine the type of immune cell differentiation. PU.1 expression is increased during granulocyte and macrophage differentiation, while it is decreased during $\mathrm{T}$ lymphocyte and B lymphocyte differentiation. The present study reviews and discusses the effects of the transcription factor PU.1 on immune cell differentiation.
\end{abstract}

\section{Contents}

1. Introduction

2. Expression of PU.1 in immune cells

3. Regulatory mechanisms of PU.1

4. Role of PU.1 in macrophage differentiation

5. PU.1 acts as a safeguard to ensure an appropriate neutrophil immune response

Correspondence to: Professor Wenxue $\mathrm{Hu}$, Department of Nephrology, Guangdong Provincial People's Hospital, Guangdong Academy of Medical Sciences, Guangdong Provincial Geriatrics Institute, 106th, Zhongshan Road II, Guangzhou, Guangdong 510080, P.R. China

E-mail: wuleihu@126.com

Key words: PU.1, differentiation, immune cells
6. Expression of PU.1 in all dendritic cells

7. Regulatory effects of PU.1 on gene expression in early $\mathrm{T}$ cells

8. PU.1 is required for B cell differentiation

9. PU.1 serves as a bridge between immune cells

10. Conclusion

\section{Introduction}

PU.1 is a member of the erythroblast transformation specific (ETS) transcription factor family. All ETS family members have a common DNA binding sequence of approximately 85 amino acids, that is the ETS domain. The sequences are highly conserved, and can be recognized by these proteins that contain the core motif 5'-GGAA/T-3' (1). However, the binding of individual ETS proteins also has its characteristics owing to the existence of the flanking sequences.

PU.1 is coded by the Spi-1 gene; Spi-1 was discovered by Moreau-Gachelin et al in 1988. Spi-1 is a putative oncogene that was isolated from a murine erythrocyte leukemia induced by the acute leukemogenic retrovirus spleen focus-forming virus (SFFV) (2).

PU.1 is a vital transcriptional regulator of hematopoietic stem cell differentiation (3); granulocytes, macrophages and lymphocytes are crucial immune cells, and they play important roles in immune system. They are involved in a serious of diseases, including inflammatory diseases, neoplastic diseases and immune diseases, such as myeloma, leukemia, systemic lupus erythematosus (SLE) and rheumatoid arthritis (RA) (4-8). Therefore, it is particularly crucial to understand the mechanisms of PU.1 in immune cells. The present study reviews the advancements made in the elucidation of the mechanisms of the transcription factor, PU.1, in immune cell differentiation.

\section{Expression of PU.1 in immune cells}

PU.1 is expressed in a tissue-specific manner and the different levels of PU.1 expression determine the type of hematopoietic stem cell differentiation (9). Thus, precise levels of PU.1 are crucial for differentiation into distinct blood lineages, and even modest decreases in its expression 
can lead to leukemogenesis. It would be of interest to determine the exact mechanisms through which target genes sense different PU.1 levels. Pospíšil et al used myeloid progenitors encoding inducible PU.1 transgene. They found that high levels of PU.1 produced macrophages, while intermediate levels of PU.1 induced differentiation into granulocyte-like cells (10). Moreover, at intermediate concentrations, PU.1 bound to high affinity binding sites in several enhancers of granulocyte genes, resulting in their successive interaction, leading to transcriptional activation (10). Nutt et al found that the expression of PU.1 was silenced in erythroid cells, but elevated in macrophages, with a sufficiently lower level in committed B cells (11). In neutrophils, PU.1 expression was found at moderately high levels. As for dendritic cells (DCs), PU.1 was expressed in all DC subsets, with a high amount of PU.1 in myeloid DCs. In comparison, plasmacytoid DCs (pDCs) characteristically expressed a low level (11). As regards T cells, some studies have found that PU.1 is decreased during $\mathrm{T}$ cell lineage differentiation $(9,12,13)$. Thus, PU.1 expression is increased during granulocyte and macrophage differentiation, while it is decreased during erythrocyte, T lymphocyte and B lymphocyte differentiation (9).

In cells of the immune system, PU.1 can activate a number of factors, such as chemokines, cytokines and cytokine receptors that are significant for immune cell differentiation and function, including cytokine receptors, such as macrophage colony stimulating factor receptor (M-CSFR), granulocyte colony stimulating factor receptor (G-CSFR), granulocyte-macrophage colony stimulating factor receptor (GM-CSFR), interleukin 3 receptor (IL-3R), Fc $\gamma$ R, cytokine CD11b and chemokines, such as CCL-22 $(9,14)$. The expression of PU.1 in immune cells is illustrated in Fig. 1.

\section{Regulatory mechanisms of PU.1}

PU.1 has several domains that are important for PU.1 to regulate immune cell differentiation. One domain is the ETS domain of 85 amino acids, which is located near the C-terminus of the protein. It is the highly conserved DNA-binding sequence that recognizes the sequence 5'-GGAA/T-3'. Other domains within PU.1 include a glutamine-rich domain and acidic residues near the N-terminal half of the protein, which are indispensable for transactivation, and a central proline, glutamic acid, serine and threonine (PEST) domain that is involved in the interaction between PU.1 and other transcription factors (15).

Furthermore, PU.1 regulates gene expression through binding to consensus sequences, not only as a monomer but also through its interaction with other transcription factors, including interferon regulatory factor (IRF)4, IRF8, $\mathrm{C} /$ enhanced binder protein $\alpha$ and $\beta(\mathrm{C} / \mathrm{EBP} \alpha$ and $\mathrm{C} / \mathrm{EBP} \beta)$ and c-Jun (16-18). However, in addition to chaperone molecules, PU.1 also has antagonistic molecules. For example, the GATA family of transcription factors can antagonize the activity of PU.1 by interacting with it. Initially, this antagonism was proposed to occur through the prevention of DNA binding (19). However, some studies have revealed that PU.1 and GATA-1 co-exist on DNA. The repression of PU.1 activity appears to involve altering the chromatin structure around the binding site (20-22).

\section{Role of PU.1 in macrophage differentiation}

In differentiated macrophages, two major phenotypes have been identified, which are of significance to the occurrence and progression of inflammation. One is a pro-inflammatory phenotype that is activated with lipopolysaccharide (LPS), either with or without interferon- $\gamma$ (known as M1 or classically activated macrophages). The other is an anti-inflammatory phenotype that is activated with IL-4 and IL-13 (known as M2 or alternatively activated macrophages). The two macrophage phenotypes have a very different metabolic profile $(23,24)$.

M1 macrophages are identified as CD64(+)CD80(+), while M2 macrophage are identified as CD11b(+)CD209(+). Polarized M1 macrophages secrete IP-10, IFN- $\gamma$, IL-8, TNF- $\alpha$, IL-1 $\beta$ and RANTES, whereas M2 macrophages secrete IL-13, CCL17 and CCL18 (20). Moreover, M2 macrophages are characterized by an abundant expression of CD163, arginase, mannose receptor (MR/CD206), chitinase-like molecules (Ym-1/2) and resistin-like molecule $\alpha$ (RELM $\alpha /$ Fizz-1) (25).

Furthermore, apart from the peroxisome proliferator-activated receptor (PPAR), Krüppel-like factor (KLF), IRF, signal transducer and activator of transcription (STAT), nuclear factor (NF)- $\kappa \mathrm{B}$ and hypoxia-inducible factor (HIF) families, and microRNAs (miRNAs or miRs) (26), PU.1 is also a critical molecule in macrophage differentiation. PU.1 plays a key role not only in M1 macrophage differentiation, but also M2 macrophage differentiation (27-30). Karpurapu et al identified a direct link between PU.1 and inflammation by establishing a bone marrow chimera model with functional PU.1 knockout phenotype in mature macrophages (28). In these mice, the expression of $\mathrm{NF}-\kappa \mathrm{B}$ activation, that mediates inflammation, was markedly attenuated in different organs compared with the wild-type (WT) mice. These findings indicated that PU.1 is required for LPS-induced classical macrophage activation. After macrophages are fully differentiated, PU.1 is also important for the survival of mature macrophages (28). Qian et al identified that PU.1 can promote alternative macrophage polarization and induce the expression of the pro-allergic factors, Ym-1 and Fizz-1, which play a role in the development of allergic inflammation (29).

The regulatory mechanisms of PU.1 in macrophage differentiation involve the prevention of polycomb repressive complex 2 (PRC2)-mediated heterochromatin formation at macrophage-specific genes, the activation of pre-existing and de novo myeloid enhancers and cell cycle arrest (30-32). E2F transcription factor 1 (E2F1) has been described to regulate genes encoding enzymes involved in lipid anabolism to promote cell cycle progression (33). However, the E2F1 mRNA transcript levels can be repressed by miR-233, that is induced by PU.1. In summary, the transcription factor, PU.1, is essential for the coordination of macrophage differentiation with cell cycle arrest (32).

$\mathrm{Pu} .1$ regulates macrophage differentiation not only as a monomer, but also through its interaction with other transcription factors, such as IRF4 (34) and c-Jun (35). Nevertheless, the levels of PU.1 can be repressed; miR-150-5p, miR-150-5p directly interact and suppresses PU.1 transcript sequences. The overexpression of miR-150-5p can suppress the PU.1 levels which affects the polarization of macrophages (36). 


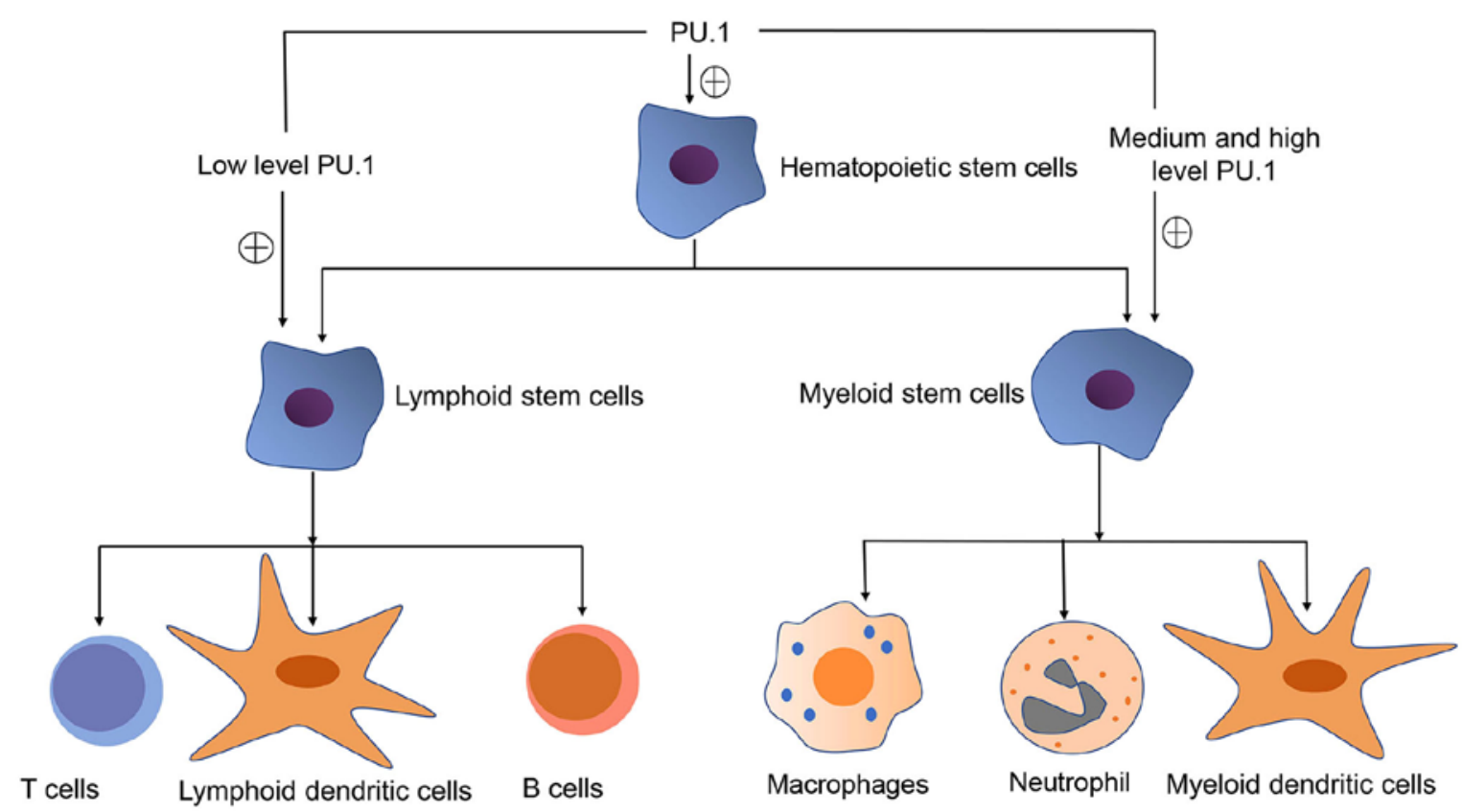

Figure 1. Expression of PU.1 in immune cells. High levels of PU.1 can induce hematopoietic stem cell differentiation into myeloid cells, such as macrophages and myeloid dendritic cells, while intermediate levels of PU.1 induce differentiation into neutrophils. Low levels of PU.1 can produce lymphoid cells, such as lymphocytes and lymphoid dendritic cells.

\section{PU.1 acts as a safeguard to ensure an appropriate neutrophil immune response}

As the master immune cells in peripheral blood, neutrophils are the first line of defense against fungal infections and bacterial infections (37). Neutrophils are also important regulators of the adaptive immune system, as they can release immune-activating or -suppressing cytokines (38).

PU.1 is recognized to be involved in neutrophil differentiation. However, the exact regulatory mechanisms involved remain unknown. Some studies have found that cell cycle arrest may play a role $(39,40)$. PU.1 can activate microtubule-associated protein 1S (MAP1S) and death-associated protein kinase 2 (DAPK2) transcription by binding to their promoter. MAP1S with a link to autophagy (a cellular recycling pathway) is induced during neutrophil differentiation (39). DAPK2 (also known as DRP-1) is crucial for the cell cycle arrest in neutrophil terminal differentiation and belongs to a family of proapoptotic $\mathrm{Ca}^{2+} /$ calmodulin-regulated serine/threonine kinases and activates programmed cell death $(40,41)$. The promotion of nuclear segmentation is also a mechanism through which PU.1 regulates neutrophil differentiation. PU.1 can control the transcription of the gene encoding lamin B receptor (LBR), an inner nuclear membrane protein, which is required for neutrophil nuclear segmentation (42). Furthermore, the PU.1/Zbtb11/Tp53 pathway is a regulator of neutrophil development (43). PU.1 is involved in neutrophil differentiation by directly activating the transcription of $\mathrm{HK} 3$ and MIR29B (44,45). In summary, PU.1 is a master transcription factor in neutrophil differentiation. However, when inappropriately activated, a prolonged immune response of neutrophils can lead to collateral tissue excessive damage and contribute to autoimmunity. Therefore, a feedback inhibitory response is required to weaken the activity of neutrophils. As an essential transcription factor in neutrophil differentiation, PU.1 can also suppress neutrophil activation via the regulation of the inflammatory epigenome of neutrophils. PU.1 inhibits enhancer accessibility via the recruitment of histone deacetylases (HDACs), thereby impeding the AP-1 transcription factor JUNB (46) that represents a key mediator of the inflammatory activation from entering chromatin (47).

Taken together, PU.1 acts as a safeguard to ensure an appropriate neutrophil immune response. It controls the simultaneous activation or inhibition in neutrophils, promoting microbial sensing and inhibiting mobilization. PU.1 exerts an effect not only on the expression of neutrophil differentiation genes, but also on genes controlling infection and inflammation (47).

\section{Expression of PU.1 in all dendritic cells}

DCs are able to recognize danger signals and undergo major alterations in gene expression to produce mediators, such as chemokines and cytokines. DCs also have the ability to degrade proteins sampled from the environment, thereby presenting peptide epitopes in the context of MHCI or MHCII, thereby stimulating $\mathrm{T}$ cells to initiate adaptive immunity (23). Therefore, DCs are pivotal in binding between innate and adaptive immunity. Steady-state DC subsets are categorized into two major lineages: pDCs and conventional DCs (cDCs). pDCs are characterized by the production of high levels of type I IFN; cDCs have two phenotypically and functionally distinct subsets: cDC1s and cDC2s $(48,49)$.

PU.1 is required for the differentiation of all DCs. cDCs express high levels of PU.1. By contrast, pDCs characteristically express a low level of PU.1 (50). DC differentiation is related to the demethylation (51) and phosphorylation of PU.1. PU.1 activity can be induced through the phosphorylation of 


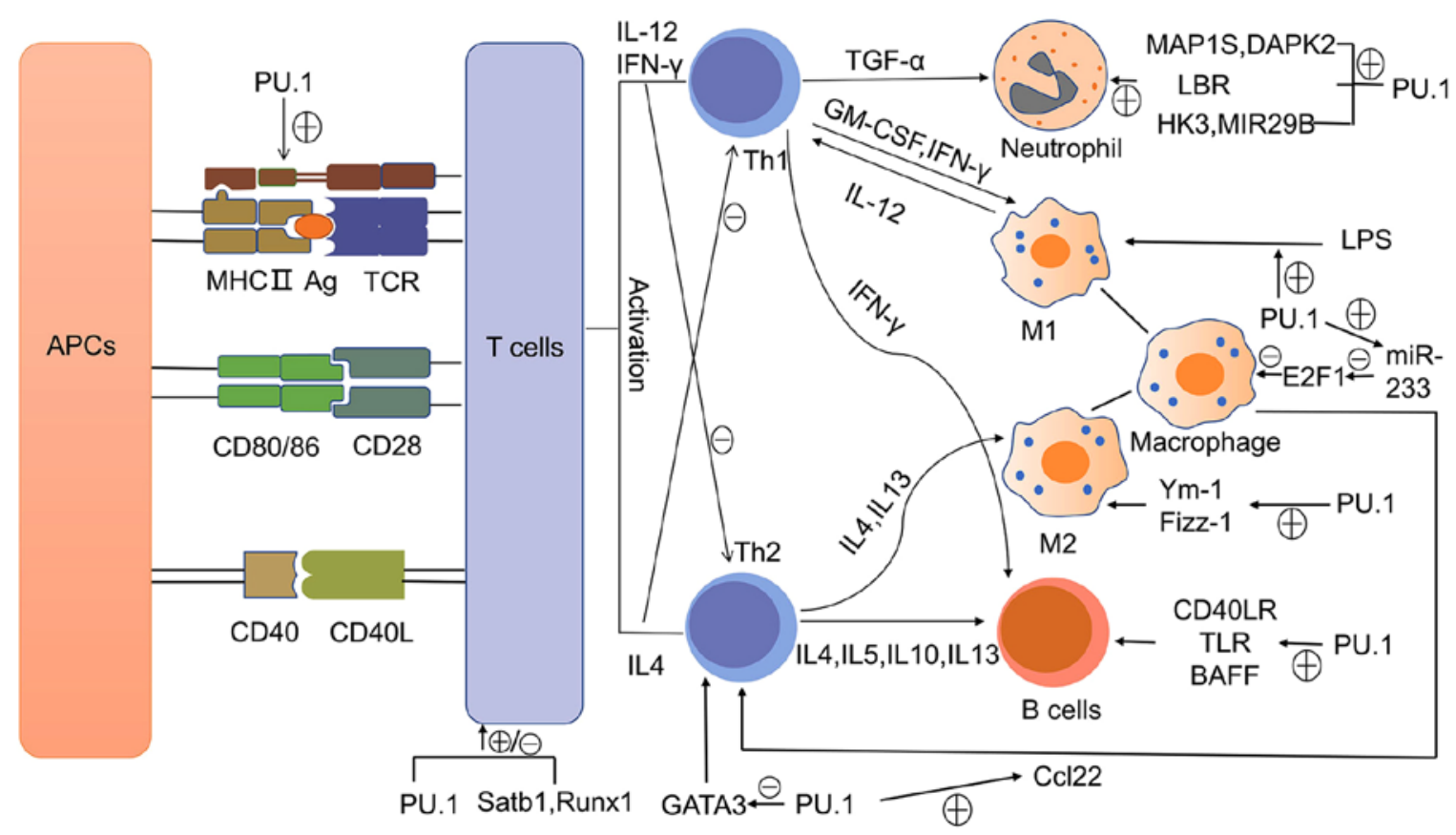

Figure 2. PU.1 regulates the differentiation of immune cells. PU.1 activates MHCII and co-stimulating factors, such as CD80/86 and CD40. APCs present the antigen to T cells through MHCII and provide co-stimulating factors, so as to activate T cells and themselves. Activated T cells induce differential immune cell differentiation by secreting various cytokines. PU.1 regulates the differentiation of immune cells through its involvement in signal transduction. APCs, antigen-presenting cells; MHCII, major histocompatibility complex class II; Satb1, SATB homeobox 1; Runx1, Runt-related transcription factor 1; IL, interleukin; IFN, interferon; TGF, transforming growth factor; GM-CSF, granulocyte-macrophage colony stimulating factor; LBR, lamin B receptor; LPS, lipopolysaccharide; E2F1, E2F transcription factor 1; Fizz-1, resistin-like molecule $\alpha$ (RELM $\alpha$ ); TKR, Toll-like receptor; BAFF, B cell-activating factor.

its transactivation domain (TAD) by $\mathrm{PKC} \delta$ to promote $\mathrm{DC}$ differentiation (52).

PU.1 is required for DC identity. For example, the leukocyte integrin, CD11c (encoded by ITGAX) is well known as a specific hallmark of DCs, which is expressed by all DC subsets. PU.1 is involved in the transcription and subsequent protein expression of CD11c by transactivating the ITGAX promoter via direct binding to the cis-element on the gene in DCs $(53,54)$.

PU.1 is required for DC function, and plays a key role in the expression of several genes that are significant for the function of DCs, including fms-like tyrosine kinase 3 (Flt3), CD80, CD86, OX40L, retinaldehyde dehydrogenase 2 (RALDH2) and major histocompatibility complex class II (MHCII) (55-58). PU.1 regulates the expression of CD80 and CD86 through binding via the upper promoter and their promoters (55). PU.1 regulates the expression of OX40L through specifically binding to the proximal region of the OX40L promoter and the PU.1-binding is constitutive, which is not affected by the TLR ligand-dependent maturation of DCs (56). PU.1 regulates the expression of RALDH2 that plays a crucial role in the development of regulatory $\mathrm{T}$ cells in mesenteric lymph nodes through binding to the RALDH2 promoter (57). The expression of $\mathrm{MHCII}$ is regulated by a cofactor termed class II transactivator (CIITA) that has three distinct promoters, pI, pIII and pIV. In cDCs, pI promoter mainly functions. PU.1 regulates CIITA-pI as a monomer, but not as a heterodimer. It not only functions as a transcription factor, but also regulates histone acetylation in the promoter region of CIITA-pI (58). In pDCs, the pIII promoter mainly functions. PU.1 plays a role by binding to Tts-motifs in the pIII in pDCs (59).
However, some studies have demonstrated that PU.1 may be recognized as a bifunctional regulator of DC functions $(60,61)$. PU.1 mainly acts as a transcriptional activator for the expression of DC-characteristic gene, while PU.1 acts partly as a transcriptional suppressor for the expression of non-characteristic gene, such as Th2 cytokines including IL-13, IL-5 in bone marrow-derived DCs. PU.1 represses Th2 cytokines expression by suppressing the expression of GATA3, that is a key regulator of Th2 differentiations (60).

\section{Regulatory effects of PU.1 on gene expression in early T cells}

During T lymphocytes, cells undergo at least three major transcription factor action stages before they are fully programmed, including the earliest 'early T cell precursors' (or Kit-high double-negative DN1), DN2 and DN3. The first transformation, commitment, separates the DN1 and DN2a phases from the DN2b and DN3 phases. This is when initially, multipotent precursors lose access to other options and become fully committed to the fate of the T cell. One factor that accounts for the majority of all open regulatory sites in the pre-commitment (DN1 and DN2a) cell genome is PU.1 (62). However, in the majority of pro-T cells, PU.1 collaborators, such as IRF4, IRF8 and C/EBP $\alpha$ are lacking $(63,64)$, with the exception of SATB homeobox 1 (Satb1) and Runt-related transcription factor 1 (Runx1). Satb1 and Runx1 interact with PU.1 in early T cells (65).

PU.1 regulates gene expression in early $\mathrm{T}$ cells positively and negatively via two distinct mechanisms: It not only opens chromatin and nucleates with transcriptional co-factors, 
such as Satb1 and Runx1 at its binding sites to form cooperative complexes, but also competitively redistributes its co-factors, often removing them from sites where they can regulate different genes $(65,66)$. The function of triggering chromatin opening occurs, particularly, at a major subgroup of its non-promoter sites, in which PU.1 can rapidly induce transposase accessibility and then recruit histone acetyltransferases (67). In summary, PU.1 regulates pro-T cell expression through its effects on chromatin opening and the deployment of other factors, and a number of its negative regulations are mediated indirectly (68).

Helper T lymphocytes, including Th1, Th2, Th9 and Th17, play an important role in the immune system, while the role of PU.1 in Th9 cells has been extensively studied lately. Ramming et al found that differentiation of Th9 cells was controlled by the unique and dynamic epigenetic modifications in the promoter region of its main transcription factor, PU.1 (69). The inhibition of repressive histone methylation can induce Th9-specific PU.1 expression (69). Goswami and Kaplan demonstrated that PU.1 promoted IL-9 expression by recruiting the Gcn5 histone acetyltransferase to the IL9 locus and promoting the expression of additional genes enriched in Th9 cells (70). However, PU.1 is degraded through selective autophagy to repress Th9 cell differentiation and reduce Th9 cell-derived IL-9 production (71).

\section{PU.1 is required for $B$ cell differentiation}

Naïve B cells develop into germinal center (GC) B cells and plasma cells (PC) following activation by cognate antigen in combination with signals from $\mathrm{T}$ helper cells and DCs (72). Therefore, the receptors through which $\mathrm{B}$ cells sense and respond to these signals are of particular importance for $\mathrm{B}$ cell differentiation. In addition, immunoglobulin class-switch recombination (CSR) is also required for early B cell differentiation into antibody-secreting plasma cells (PCs) (73).

PU.1 as a critical transcription factor of ETS family and regulates the expression of several components of the $\mathrm{B}$ cell receptor signaling pathway and the receptors for $\mathrm{CD} 40 \mathrm{~L}$, Toll-like receptor (TLR) ligands and B cell-activating factor (BAFF) (74). Moreover, PU.1 also regulates the expression of genes that are involved in immunoglobulin gene rearrangement (75). Thus, PU.1 is required for gene expression during $B$ cell differentiation.

The regulatory effects of PU.1 on cell differentiation are dependent on its DNA-binding ability and its synergism with other transcription factors, such as IRF4. PU.1 can bind to IRF4 and IRF8 at composite ETS-interferon consensus element (EICE) sites to regulate the immunoglobulin class switch, recombination and cell differentiation $(76,77)$. The DNA-binding ability can be enhanced by the histone acetyltransferases, CBP and EP300, by mediating PU.1 acetylation (78). However, SPIC weakens the DNA-binding ability of PU.1 by binding to regulatory elements similar to PU.1 binding in pre-B cells, resulting in PU.1 translocation from these regions; Bcl-2-associated transcription factor1 (BCLAF1) is recruited to gene-regulatory elements, thus inhibiting the expression of important B developmental genes (79). In addition to SPIC, E2A also weakens the DNA-binding ability of PU.1 (80). In summary, PU.1 is required for B cell differentiation.

\section{PU.1 serves as a bridge between immune cells}

Immune cells are important members of the immune system, they are independent and related to each other, and PU.1 serves as a bridge between them. The concentration of the PU.1 transcription factor affects the development of myeloid/lymphoid lineage. A high level of PU.1 promotes the acquisition of myeloid cell fate at the expense of B cell differentiation. Myelopoiesis may require high levels of PU.1 to overcome the inhibition of PU.1 activity by transcription factors that promote B cell development. Rogers et al demonstrated that E2A can antagonize PU.1 activity to direct B cell development, but high levels PU.1 can direct myeloid differentiation through overcoming this antagonism (80). Furthermore, PU.1 can regulate the differentiation of $\mathrm{T}$ lymphocytes by promoting the function of antigen-presenting cells (APCs), including mature DCs, B cells and macrophages. For example, PU.1 regulates the gene expression of the chemokine, $\mathrm{Ccl} 22$, in DCs and macrophages, and $\mathrm{Ccl} 22$ can mediate Th2 cell development by binding to the receptor, CCR4, in Th2 cells, thus regulating the development of atopic dermatitis (AD) and asthma (14). PU.1 is transcriptional activator of the CD80, CD86 and OX40L genes in APCs, which are the co-stimulatory molecules predominantly involved in Th2 and Tfh cell differentiation (81). Taken together, different levels of PU.1 tend to differentially affect immune cell differentiation, and PU.1 in APCs is required for precise T cell stimulation and differentiation. PU.1 serves as the bridge between immune cells. The effects of the PU.1 transcription factor on immune cell differentiation are illustrated in Fig. 2.

\section{Conclusion}

Immune cells play an important role in the occurrence and development of a serious of diseases, including inflammatory diseases, neoplastic diseases and immune diseases. The transcription factor, PU.1, is required in immune cell differentiation. In view of the important position of PU.1 in the regulation of the immune system, the elucidation of its regulatory mechanisms in immune cells may provide new clues and may lead to the development of novel strategies with which to reduce the damage induced by inflammation to organs. This may thus lead to more effective therapeutic strategies for the treatment of inflammatory diseases and immune-mediated diseases mediated by various immune cells.

\section{Acknowledgements}

Not applicable.

\section{Funding}

The present study was supported by grants from the National Natural Science Foundation of China (no. 81700670) and Natural Science Foundation of Guangdong Province (no. 2019A1515011594).

\section{Availability of data and materials}

Not applicable. 


\section{Authors' contributions}

GL, WHao and WHu contributed to the conception and design of the present review. GL contributed to the writing and drafting of the manuscript. WHao and WHu contributed to the critical revision of the manuscript for important intellectual content. All authors read and approved the final manuscript.

\section{Ethics approval and consent to participate}

Not applicable.

\section{Patient consent for publication}

Not applicable.

\section{Competing interests}

The authors declare that they have no competing interests.

\section{References}

1. Karim FD, Urness LD, Thummel CS, Klemsz MJ, McKercher SR, Celada A, Van Beveren C, Maki RA, Gunther CV, Nye JA, et al: The ETS-domain: A new DNA-binding motif that recognizes a purine-rich core DNA sequence. Genes Dev 4: 1451-1453, 1990.

2. Moreau-Gachelin F, Tavitian A and Tambourin P: Spi1 is a putative oncogene in virally induced murine erythroleukaemias. Nature 331: 277-280, 1988

3. Gupta P, Gurudutta GU, Saluja D and Tripathi RP: PU.1 and partners: Regulation of haematopoietic stem cell fate in normal and malignant haematopoiesis. J Cell Mol Med 13: 4349-4363, 2009.

4. Ueno N, Nishimura N, Ueno S, Endo S, Tatetsu H, Hirata S, Hata $\mathrm{H}$, Matsuoka M, Mitsuya $\mathrm{H}$ and Okuno Y: PU.1 acts as tumor suppressor for myeloma cells through direct transcriptional repression of IRF4. Oncogene 36: 4481-4497, 2017.

5. Tenen DG, Hromas R, Licht JD and Zhang DE: Transcription factors, normal myeloid development, and leukemia. Blood 90 489-519, 1997

6. Batista CR, Lim M, Laramée AS, Abu-Sardanah F, Xu LS, Hossain R, Bell Gl, Hess DA and DeKoter RP: Driver mutations in Janus kinases in a mouse model of B-cell leukemia induced by deletion of PU.1 and Spi-B. Blood Adv 2: 2798-2810, 2018.

7. Dozmorov MG, Wren JD and Alarcón-Riquelme ME: Epigenomic elements enriched in the promoters of autoimmunity susceptibility genes. Epigenetics 9: 276-285, 2014.

8. Alivernini S, Kurowska-Stolarska M, Tolusso B, Benvenuto R, Elmesmari A, Canestri S, Petricca L, Mangoni A, Fedele AL, Di Mario C, et al: MicroRNA-155 influences B-cell function through PU.1 in rheumatoid arthritis. Nat Commun 7: 12970, 2016.

9. Turkistany SA and DeKoter RP: The transcription factor PU.1 is a critical regulator of cellular communication in the immune system. Arch Immunol Ther Exp (Warsz) 59: 431-440, 2011.

10. Pospíśil V, Krsmanovic P, Chramostová K, Vokurka K, Laslo P and Stopka T: Graded PU.1 levels activate granulocyte vs. macrophage genes via multiple(super) enhancer elements. Exp Hematol 76 (Suppl): S82, 2019.

11. Nutt SL, Metcalf D, D'Amico A, Polli M and Wu L: Dynamic regulation of PU.1 expression in multipotent hematopoietic progenitors. Exp Med 201: 221-231, 2005.

12. Yashiro T, Takeuchi H, Kasakura K and Nishiyama C: PU.1 regulates $\mathrm{Ccr} 7$ gene expression by binding to its promoter in naïve $\mathrm{CD}^{+} \mathrm{T}$ cells. FEBS Open Bio 10: 1115-1121, 2020.

13. Anderson MK, Weiss AH, Hernandez-Hoyos G, Dionne CJ and Rothenberg EV: Constitutive expression of PU.1 in fetal hematopoietic progenitors blocks $\mathrm{T}$ cell development at the pro-T cell stage. Immunity 16: 285-296, 2002.
14. Yashiro T, Nakano S, Nomura K, Uchida Y, Kasakura K and Nishiyama C: A transcription factor PU.1 is critical for Ccl22 gene expression in dendritic cells and macrophages. Sci Rep 9: $1161,2019$.

15. Lloberas J, Soler C and Celada A: The key role of PU.1/SPI-1 in B cells, myeloid cells and macrophages. Immunol Today 20: 184-189, 1999.

16. Petrovick MS, Hiebert SW, Friedman AD, Hetherington CJ, Tenen DG and Zhang DE: Multiple functional domains of AML1: PU.1 and C/EBPalpha synergize with different regions of AML1. Mol Cell Biol 18: 3915-3925, 1998.

17. Marecki S and Fenton MJ: PU.1/interferon regulatory factor interactions: Mechanisms of transcriptional regulation. Cell Biochem Biophys 33: 127-148, 2000.

18. Behre G, Whitmarsh AJ, Coghlan MP, Hoang T, Carpenter CL, Zhang DE, Davis RJ and Tenen DG: c-Jun is a JNK-independent coactivator of the PU.1 transcription factor. J Biol Chem 274: 4939-4946, 1999.

19. Zhang P, Zhang X, Iwama A, Yu C, Smith KA, Mueller BU, Narravula S, Torbett BE, Orkin SH and Tenen DG: PU.1 inhibits GATA-1 function and erythroid differentiation by blocking GATA-1 DNA binding. Blood 96: 2641-2648, 2000.

20. Rekhtman N, Choe KS, Matushansky I, Murray S, Stopka T and Skoultchi AI: PU.1 and pRB interact and cooperate to repress GATA-1 and block erythroid differentiation. Mol Cell Biol 23: 7460-7474, 2003

21. Stopka T, Amanatullah DF, Papetti M and Skoultchi AI: PU.1 inhibits the erythroid program by binding to GATA-1 on DNA and creating a repressive chromatin structure. EMBO J 24: 3712-3723, 2005.

22. Burda P, Laslo P and Stopka T: The role of PU.1 and GATA-1 transcription factors during normal and leukemogenic hematopoiesis. Leukemia 24: 1249-1257, 2010.

23. O'Neill LA and Pearce EJ: Immunometabolism governs dendritic cell and macrophage function. J Exp Med 213: 15-23, 2016.

24. Tarique AA, Logan J, Thomas E, Holt PG, Sly PD and Fantino E: Phenotypic, functional, and plasticity features of classical and alternatively activated human macrophages. Am J Respir Cell Mol Biol 53: 676-688, 2015.

25. Nair MG, Gallagher IJ, Taylor MD, Loke P, Coulson PS, Wilson RA, Maizels RM and Allen JE: Chitinase and Fizz family members are a generalized feature of nematode infection with selective upregulation of Ym1 and Fizz1 by antigen-presenting cells. Infect Immun 73: 385-394, 2005.

26. Wang N, Liang $\mathrm{H}$ and Zen $\mathrm{K}$ : Molecular mechanisms that influence the macrophage m1-m2 polarization balance: Front Immunol 5: 614, 2014.

27. Juhas U, Ryba-Stanisławowska M, Szargiej P and Myśliwska J: Different pathways of macrophage activation and polarization. Postepy Hig Med Dosw (Online) 69: 496-502, 2015.

28. Karpurapu M, Wang X, Deng J, Park H, Xiao L, Sadikot RT, Frey RS, Maus UA, Park GY, Scott EW and Christman JW: Functional PU.1 in macrophages has a pivotal role in NF- $\kappa$ B activation and neutrophilic lung inflammation during endotoxemia. Blood 118: 5255-5266, 2011.

29. Qian F, Deng J, Lee YG, Zhu J, Karpurapu M, Chung S, Zheng JN, Xiao L, Park GY and Christman JW: The transcription factor PU.1 promotes alternative macrophage polarization and asthmatic airway inflammation. J Mol Cell Biol 7: 557-567, 2015.

30. Tagore M, McAndrew MJ, Gjidoda A and Floer M: The lineage-specific transcription factor PU.1 prevents polycomb-mediated heterochromatin formation at macrophage-specific genes. Mol Cell Biol 35: 2610-2625, 2015.

31. van Oevelen C, Collombet S, Vicent G, Hoogenkamp M, Lepoivre C, Badeaux A, Bussmann L, Sardina JL, Thieffry D, Beato $\mathrm{M}$, et al: $\mathrm{C} / \mathrm{EBP} \alpha$ activates pre-existing and de novo macrophage enhancers during induced Pre-B cell transdifferentiation and myelopoiesis. Stem Cell Reports 5: 232-247, 2015.

32. Solomon LA, Podder S, He J, Jackson-Chornenki NL, Gibson K, Ziliotto RG, Rhee J and DeKoter RP: Coordination of myeloid differentiation with reduced cell cycle progression by PU.1 induction of MicroRNAs targeting cell cycle regulators and lipid anabolism. Mol Cell Biol 37: e00013-17, 2017.

33. Denechaud PD, Lopez-Mejia IC, Giralt A, Lai Q, Blanchet E, Delacuisine B, Nicolay BN, Dyson NJ, Bonner C, Pattou F, et al: E2F1 mediates sustained lipogenesis and contributes to hepatic steatosis. J Clin Invest 126: 137-150, 2016. 
34. Eguchi J, Kong X, Tenta M, Wang X, Kang S and Rosen ED: Interferon regulatory factor 4 regulates obesity-induced inflammation through regulation of adipose tissue macrophage polarization. Diabetes 62: 3394-3403, 2013.

35. Shen C, Chen MT, Zhang XH, Yin XL, Ning HM, Su R, Lin HS, Song L, Wang F, Ma YN, et al: The PU.1-modulated MicroRNA-22 is a regulator of monocyte/macrophage differentiation and acute myeloid leukemia. PLoS Genet 12: e1006259, 2016.

36. Shakerian L, Ghorbani S, Talebi $F$ and Noorbakhsh F: MicroRNA-150 targets PU.1 and regulates macrophage differentiation and function in experimental autoimmune encephalomyelitis. J Neuroimmunol 323: 167-174, 2018.

37. Kruger P, Saffarzadeh M, Weber AN, Rieber N, Radsak M, von Bernuth H, Benarafa C, Roos D, Skokowa J and Hartl D. Neutrophils: Between host defence, immune modulation, and tissue injury. PLoS Pathog 11: e1004651, 2015

38. Mantovani A, Cassatella MA, Costantini C and Jaillon S Neutrophils in the activation and regulation of innate and adaptive immunity. Nat Rev Immunol 11: 519-531, 2011.

39. Haimovici A, Brigger D, Torbett BE, Fey MF and Tschan MP Induction of the autophagy-associated gene MAP1S via PU.1 supports APL differentiation. Leuk Res 38: 1041-1047, 2014.

40. Humbert M, Federzoni EA, Britschgi A, Schläfli AM, Valk PJ, Kaufmann T, Haferlach T, Behre G, Simon HU, Torbett BE, et al: The tumor suppressor gene DAPK 2 is induced by the myeloid transcription factors PU.1 and $\mathrm{C} / \mathrm{EBP} \alpha$ during granulocytic differentiation but repressed by PML-RAR $\alpha$ in APL. J Leukoc Biol 95: 83-93, 2014

41. Bialik S and Kimchi A: The death-associated protein kinases: Structure, function, and beyond. Annu Rev Biochem 75: 189-210, 2006.

42. Malu K, Garhwal R, Pelletier MG, Gotur D, Halene S, Zwerger M, Yang ZF, Rosmarin AG and Gaines P: Cooperative activity of GABP with PU.1 or $\mathrm{C} / \mathrm{EBP} \varepsilon$ regulates lamin $\mathrm{B}$ receptor gene expression, implicating their roles in granulocyte nuclear maturation. J Immunol 197: 910-922, 2016.

43. Keightley MC, Carradice DP, Layton JE, Pase L, Bertrand JY, Wittig JG, Dakic A, Badrock AP, Cole NJ, Traver D, et al: The Pu.1 target gene Zbtb11 regulates neutrophil development through its integrase-like HHCC zinc finger. Nat Commun 8: 14911,2017.

44. Federzoni EA, Valk PJ, Torbett BE, Haferlach T, Löwenberg B, Fey MF and Tschan MP: PU.1 is linking the glycolytic enzyme HK3 in neutrophil differentiation and survival of APL cells. Blood 119: 4963-4970, 2012.

45. Batliner J, Buehrer E, Federzoni EA, Jenal M, Tobler A, Torbett BE, Fey MF and Tschan MP: Transcriptional regulation of MIR29B by PU.1 (SPI1) and MYC during neutrophil differentiation of acute promyelocytic leukaemia cells. $\mathrm{Br}$ J Haematol 157: 270-274, 2012.

46. Fontana MF, Baccarella A, Pancholi N, Pufall MA, Herbert DR and Kim CC: JUNB is a key transcriptional modulator of macrophage activation. J Immunol 194: 177-186, 2014.

47. Fischer J, Walter C, Tönges A, Aleth H, Jordão MJC, Leddin M, Gröning V, Erdmann T, Lenz G, Roth J, et al: Safeguard function of PU.1 shapes the inflammatory epigenome of neutrophils. Nat Immunol 20: 546-558, 2019.

48. Guilliams M, Ginhoux F, Jakubzick C, Naik SH, Onai N, Schraml BU, Segura E, Tussiwand R and Yona S: Dendritic cells, monocytes and macrophages: A unified nomenclature based on ontogeny. Nat Rev Immunol 14: 571-578, 2014.

49. Belz GT and Nutt SL: Transcriptional programming of the dendritic cell network. Nat Rev Immunol 12: 101-113, 2012

50. Carotta S, Dakic A, D'Amico A, Pang SH, Greig KT, Nutt SL and $\mathrm{Wu}$ L: The transcription factor PU.1 controls dendritic cell development and Flt3 cytokine receptor expression in a dose-dependent manner. Immunity 32: 628-641, 2010.

51. Lapko N,Zawadka M,Polosak J, Worthen GS, Danet-Desnoyers G Puzianowska-Kuźnicka M and Laudanski K: Long-term monocyte dysfunction after sepsis in humanized mice is related to persisted activation of macrophage-colony stimulation factor (M-CSF) and demethylation of PU.1, and it can be reversed by blocking M-CSF in vitro or by transplanting naïve autologous stem cells in vivo. Front Immunol 8: 401, 2017.

52. Hamdorf M, Berger A, Schüle S, Reinhardt J and Flory E: PKCס-induced PU.1 phosphorylation promotes hematopoietic stem cell differentiation to dendritic cells. Stem Cells 29: 297-306, 2011
53. Yashiro T, Kasakura K, Oda $\mathrm{Y}$, Kitamura N, Inoue A, Nakamura S, Yokoyama H, Fukuyama K, Hara M, Ogawa H, et al: The hematopoietic cell-specific transcription factor PU.1 is critical for expression of CD11c. Int Immunol 29: 87-94, 2017.

54. Zhu XJ, Yang ZF, Chen Y, Wang J and Rosmarin AG: PU.1 is essential for CD11c expression in CD8(+)/CD8(-) lymphoid and monocyte-derived dendritic cells during GM-CSF or FLT3L-induced differentiation. PLoS One 7: e52141, 2017.

55. Kanada S, Nishiyama C, Nakano N, Suzuki R, Maeda K, Hara M, Kitamura N, Ogawa H and Okumura K: Critical role of transcription factor PU.1 in the expression of CD80 and CD86 on dendritic cells. Blood 117: 2211-2222, 2011.

56. Yashiro T, Hara M, Ogawa $\mathrm{H}$, Okumura $\mathrm{K}$ and Nishiyama $\mathrm{C}$ : Critical role of transcription factor PU.1 in the function of the OX40L/TNFSF4 promoter in dendritic cells. Sci Rep 6: 34825 , 2016.

57. Yashiro T, Yamaguchi M, Watanuki Y, Kasakura $\mathrm{K}$ and Nishiyama C: The transcription factors PU.1 and IRF4 determine dendritic cell-specific expression of RALDH2. J Immunol 201: 3677-3682, 2018

58. Kitamura N, Yokoyama H, Yashiro T, Nakano N, Nishiyama M, Kanada S, Fukai T, Hara M, Ikeda S, Ogawa H, et al: Role of PU.1 in MHC class II expression through transcriptional regulation of class II transactivator pI in dendritic cells. J Allergy Clin Immunol 129: 814-824.e6, 2012.

59. Miura R, Kasakura K, Nakano N, Hara M, Maeda K, Okumura K, Ogawa H, Yashiro T and Nishiyama C: Role of PU.1 in MHC class II expression via CIITA transcription in plasmacytoid dendritic cells. PLoS One 11: e0154094, 2016.

60. Yashiro T, Kubo M, Ogawa H, Okumura K and Nishiyama C: PU.1 suppresses Th2 cytokine expression via silencing of GATA3 transcription in dendritic cells. PLoS One 10: e0137699, 2015.

61. Nakano N, Nishiyama C, Kanada S, Niwa Y, Shimokawa N, Ushio $\mathrm{H}$, Nishiyama $M$, Okumura $\mathrm{K}$ and Ogawa $\mathrm{H}$ : Involvement of mast cells in IL-12/23 p40 production is essential for survival from polymicrobial infections. Blood 109: 4846-4855, 2007.

62. Yui MA and Rothenberg EV: Developmental gene networks: A triathlon on the course to T cell identity. Nat Rev Immunol 14: 529-545, 2014.

63. Heinz S, Romanoski CE, Benner C, Allison KA, Kaikkonen MU, Orozco LD and Glass CK: Effect of natural genetic variation on enhancer selection and function. Nature 503: 487-492, 2013.

64. Natoli G, Ghisletti S and Barozzi I: The genomic landscapes of inflammation. Genes Dev 25: 101-106, 2011.

65. Hosokawa H, Ungerbäck J, Wang X, Matsumoto M, Nakayama KI, Cohen SM, Tanaka T and Rothenberg EV: Transcription factor PU.1 represses and activates gene expression in early $\mathrm{T}$ cells by redirecting partner transcription factor binding. Immunity 49 : $782,2018$.

66. Rothenberg EV, Hosokawa $\mathrm{H}$ and Ungerbäck J: Mechanisms of action of hematopoietic transcription factor PU.1 in initiation of T-cell development. Front Immunol 10: 228, 2019.

67. Ungerbäck J, Hosokawa H, Wang X, Strid T, Williams BA, Sigvardsson $\mathrm{M}$ and Rothenberg EV: Pioneering, chromatin remodeling, and epigenetic constraint in early T-cell gene regulation by SPI1 (PU.1). Genome Res 28: 1508-1519, 2018.

68. Champhekar A, Damle SS, Freedman G, Carotta S, Nutt SL and Rothenberg EV: Regulation of early T-lineage gene expression and developmental progression by the progenitor cell transcription factor PU.1. Genes Dev 29: 832-848, 2015.

69. Ramming A, Druzd D, Leipe J, Schulze-Koops H and Skapenko A: Maturation-related histone modifications in the PU.1 promoter regulate Th9-cell development. Blood 119: 4665-4674, 2012.

70. Goswami R and Kaplan MH: Gen5 is required for PU.1-dependent IL-9 induction in Th9 cells. J Immunol 189: 3026-3033, 2012.

71. Rivera Vargas T, Cai Z, Shen Y, Dosset M, Benoit-Lizon I, Martin T, Roussey A, Flavell RA, Ghiringhelli F and Apetoh L: Selective degradation of PU.1 during autophagy represses the differentiation and antitumour activity of TH9 cells. Nat Commun 8: 559, 2017.

72. Goodnow CC, Vinuesa CG, Randall KL, Mackay F and Brink R: Control systems and decision making for antibody production. Nat Immunol 11: 681-688, 2010.

73. Carotta S, Willis SN, Hasbold J, Inouye M, Pang SH, Emslie D, Light A, Chopin M, Shi W, Wang H, et al: The transcription factors IRF8 and PU.1 negatively regulate plasma cell differentiation. J Exp Med 211: 2169-2181, 2014. 
74. Willis SN, Tellier J,Liao Y,Trezise S,Light A, O'Donnell K, GarrettSinha LA, Shi W, Tarlinton DM and Nutt SL: Environmental sensing by mature B cells is controlled by the transcription factors PU.1 and SpiB. Nat Commun 8: 1426, 2017.

75. Batista CR, Li SK, Xu LS, Solomon LA and DeKoter RP: PU.1 regulates Ig light chain transcription and rearrangement in Pre-B cells during B cell development. J Immunol 198: 1565-1574 2017.

76. Ochiai K, Maienschein-Cline M, Simonetti G, Chen J, Rosenthal R, Brink R, Chong AS, Klein U, Dinner AR, Singh H and Sciammas R: Transcriptional regulation of germinal center B and plasma cell fates by dynamical control of IRF4. Immunity 38 918-929, 2013.

77. Pang SH, Minnich M, Gangatirkar P, Zheng Z, Ebert A, Song G, Dickins RA, Corcoran LM, Mullighan CG, Busslinger M, et al PU.1 cooperates with IRF4 and IRF8 to suppress pre-B-cell leukemia. Leukemia 30: 1375-1387, 2016.
78. Scialdone A, Khazaei S, Hasni MS, Lennartsson A, Gullberg U and Drott K: Depletion of the transcriptional coactivators CREB-binding protein or EP300 downregulates CD20 in diffuse large B-cell lymphoma cells and impairs the cytotoxic effects of anti-CD20 antibodies. Exp Hematol 79: 35-46.e1, 2019.

79. Soodgupta D, White LS, Yang W, Johnston R, Andrews JM, Kohyama M, Murphy KM, Mosammaparast N, Payton JE and Bednarski JJ: RAG-mediated DNA breaks attenuate PU.1 activity in early B cells through activation of a SPIC-BCLAF1 complex. Cell Rep 29: 829-843.e5, 2019.

80. Rogers JH, Owens KS, Kurkewich J, Klopfenstein N, Iyer SR, Simon MC and Dahl R: E2A antagonizes PU.1 activity through inhibition of DNA binding. Biomed Res Int 2016: 3983686, 2016.

81. Laslo P, Spooner CJ, Warmflash A, Lanck DW, Lee HJ, Sciammas R, Gantner BN, Dinner AR and Singh H: Multilineage transcriptional priming and determination of alternate hematopoietic cell fates. Cell 126: 755-766, 2006. 